\title{
Reconciliation ecology and the future of species diversity
}

\author{
Michael L. Rosenzweig
}

\begin{abstract}
Species-area relationships (SPARs) dictate a sea change in the strategies of biodiversity conservation. SPARs exist at three ecological scales: Sample-area SPARs (a larger area within a biogeographical province will tend to include more habitat types, and thus more species, than a smaller one), Archipelagic SPARs (the islands of an archipelago show SPARs that combine the habitatsampling process with the problem of dispersal to an island), and Interprovincial SPARs (other things being equal, the speciation rates of larger biogeographical provinces are higher and their extinction rates are lower, leading to diversities in proportion to provincial area). SPARs are the products of steady-state dynamics in diversity, and such dynamics appears to have characterized the earth for most of the last 500 million years. As
\end{abstract}

people reduce the area available to wild species, they impose a linear reduction of the earth's species diversity that will follow the largest of these scales, i.e. each $1 \%$ reduction of natural area will cost about $1 \%$ of steadystate diversity. Reserving small tracts of wild habitat can only delay these reductions. But we can stop most of them by redesigning anthropogenic habitats so that their use is compatible with use by a broad array of other species. That is reconciliation ecology. Many pilot projects, whether intentionally or inadvertently espousing reconciliation ecology, are demonstrating that it can be done.

Keywords Countryside biogeography, mass extinction, reconciliation ecology, species-area curve, species diversity, steady state.

\section{Introduction}

Alexander von Humboldt (1807) provided the first hint of one of ecology's most pervasive rules: larger areas contain more species than do small ones. Many ecologists see that rule - the species-area relationship - as one of ecology's very few general laws (e.g. Lawton, 1999; Rosenzweig \& Ziv, 1999).

Over the past two centuries ecologists have learned a lot about species-area relationships. What we know about them turns out to be crucial to conservation. As the reader will soon appreciate, it warns us that current theories of conservation severely underestimate the proportion of diversity that is threatened. But it also directs us to a new strategy of conservation biology that I call reconciliation ecology. Rather than insist on protecting habitat from human use, reconciliation ecology works in and with the human dominated habitats that cover most of the terrestrial surface of the Earth. Reconciliation ecology gives us the realistic hope that we can prevent most losses of species.

Because reconciliation ecology grows out of a thorough understanding of species-area relationships (SPARs), I will spend the initial two-thirds of this paper exploring

Michael L. Rosenzweig Department of Ecology \& Evolutionary Biology, University of Arizona, Tucson, AZ, 85721-0088, USA.

E-mail: scarab@u.arizona.edu

Received 14 August 2002. Revision requested 9 January 2003. Accepted 10 February 2003 their fundamentals. With this knowledge, the reader will appreciate how the science of species diversity leads inexorably to the use of reconciliation ecology for conserving species. Conservation biology can succeed in minimizing extinction losses, but to do so it must insist that reconciliation become a major element in its toolbox.

\section{Species-area equations}

Ecologists began by describing the species-area pattern quantitatively. Two botanists, Alphonse de Candolle and Hewett C. Watson, noticed a mathematical regularity in the way that the diversity of plants depends on area. The Danish ecologist Olaf Arrhenius (1921) and the American Frank Preston (1960) formalized the relationship by fitting it with a power equation:

$S=C A^{z}$

where $S$ is the number of species, $A$ is the area, and $C$ and $z$ are constants. For convenience, ecologists generally employ the logarithmic form of this equation:

$\log S=c+z \log A$

where $c=\log C$. (Note that I do not use the jargon term 'species richness.' To understand why, see Rosenzweig et al., 2003).

The species-area power equation or SPAR can be fitted to an immense amount of data (Rosenzweig, 1995). It fits plant and animal diversities. It fits islands and continents, and sample areas within continents. It even 
fits data from the fossil record. Ecologists are not sure why a power equation fits islands or continents, but we do now have a successful mathematical theory for areas within a province. McGill \& Collins (2003) deduced the species-area curve within provinces from four assumptions:

- The geographical range of each species is independently located with respect to all others.

- Species vary in abundance with respect to each other.

- Species have a minimum abundance.

- Each species' abundance varies significantly across its own range, being relatively scarce more often than relatively common ('relatively' means with respect to its own average abundance).

Data support all four assumptions. From them, McGill shows that there is a species-area curve and that it approximates a power equation whose $z$-value ranges between 0.05 and 0.25 with a mean of about 0.15 .

McGill's theory improves that of Leitner, which required knowledge of the relationship between abundance and range size (Leitner \& Rosenzweig, 1997). McGill's theory also predicts the abundance-range-size relationship. Leitner's theory in turn supplanted that of Preston (1962) (elaborated and extended by May, 1975). Leitner found two cryptic errors in the Preston-May proofs, errors that vitiated them. Both McGill's and Leitner's theory show that the power equation is merely a good fit rather than an exact description of the species-area curve. That it is a good fit should not be too surprising because power equations are very plastic curves and fit a host of monotonic relationships.

Other ingenious attempts at a SPAR theory exist, but all have their problems, problems mostly outside the scope of this paper (Wissel \& Maier, 1992; Durrett \& Levin, 1996; Harte et al., 1999; Hubbell, 2001). Yet I must mention one frequent problem: the assumption of a single habitat type for all places. No model can possibly account for a pattern known to be caused by a variable that the model does not use (this is true no matter how well such a model may fit the data). Yet we certainly know that the species-area relationship within a province depends on the inclusion of more habitats in larger areas (Williams, 1964). McGill's theory incorporates habitat variation in its assumption that each species' abundance varies significantly across its own range.

\section{Scales of the species-area curve}

SPAR is actually four puzzles and their pieces had been mixed up together as if they belonged to the same puzzle. Thus, the SPAR puzzle pieces first had to be separated (Rosenzweig, 1995). The key was realizing that a variety of different processes determine $S$ as a function of area.
Each of these processes produces SPARs with $z$-values in a restricted range, and the ranges abut, covering virtually the entire unit interval. Three of the puzzles fit together like a triptych. I will review all four SPAR puzzles and the processes that produce them.

\section{Sample-size SPARs}

Determining the number of species in an area requires sampling. Sampling comes with a bias, i.e. the larger the number of individuals identified, the greater the number of species in the sample. Usually, more individuals will be identified from a larger area than a smaller one. A SPAR generated by statistical sampling artifacts holds no biological interest. Nonetheless, one must be able to recognize such SPARs and eliminate them from further consideration. Fisher et al. (1943) showed us one powerful way to do this, devising a statistic called Fisher's $\alpha$ that is almost insensitive to sample size but does vary with S. Burnham \& Overton (1979) and Lee \& Chao (1994) have introduced other successful bias reducing statistics. These can be calculated using free software packages (WS2M at http://eebweb.arizona.edu/diversity, and EstimateS at http://viceroy.eeb.uconn.edu/EstimateS). Sample-size SPARs tend to have the smallest $z$-values. All those I have encountered have $z \leqslant 0.12$ (Rosenzweig, 1995).

\section{Sample-area SPAR}

All species have habitat requirements that restrict them in space. A larger area will tend to include more habitat types than a smaller one (Williams, 1943). Thus SPARs emerge from different-size samples within the same biological region. They tend to have $z$-values of $0.1-0.2$ (Rosenzweig, 1995).

\section{Archipelagic SPARs}

The islands of an archipelago combine the habitat-sampling process with another process, which I review below. Their SPARs have z-values of 0.25-0.55 (Rosenzweig, 1995).

\section{Interprovincial SPARs}

Biogeographical provinces of similar environment, such as wet tropical forests, have diversities in proportion to their areas. A biogeographical province is a region whose species have evolved within it, rather than immigrating from somewhere else. Although the concept is merely an ideal - every place has at least a few species that arrived as immigrants - it is close to true in many places, such as different continents or well-separated periods in 
the history of life. Interprovincial SPARs are much less common than those for archipelagos, but the law they follow is clear. The $z$-values of interprovincial SPARs begin at 0.6 and range upwards, with most about 0.9 to 1 (Rosenzweig, 1995, 2001). Fig. 1 shows a recently obtained example. Diversity in provinces appears to have been following such a law for hundreds of millions of years (Rosenzweig \& Ziv, 1999), and we have no evidence to suggest that this law has been altered. On the contrary, because they appear to be so reliable and because they predict diversity far into the future, interprovincial $z$-values will turn out to be the most useful to conservation biologists.

\section{What makes z-values different?}

To understand the three SPARs of Fig. 2 (and their differences), we need to connect the state variable we call species diversity to its derivatives. Recognizing that, and beginning the journey to accomplish it, was one of the greatest achievements of MacArthur and Wilson (1967), who applied dynamic analysis to the problem of island diversities. They carefully defined the two derivatives that should matter most: the rate at which species not on an island arrive on it, and the rate at which species on an island become extinct there. Then, in search of a selfregulating system, they asked how these rates should vary with diversity itself.

Their result was powerful and robust: An island with no species can suffer no extinctions. An island with all

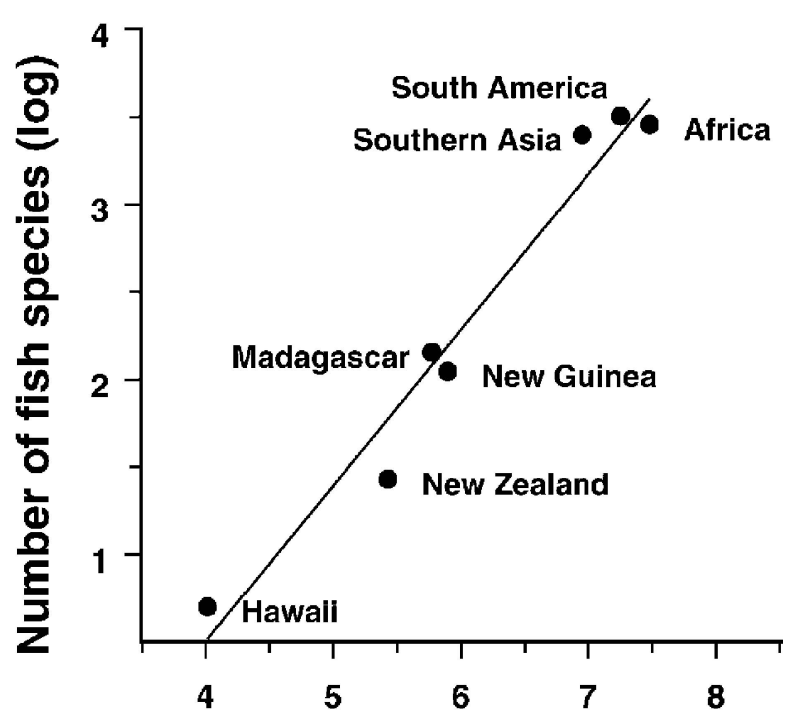

\section{Area in $\mathbf{k m}^{2}(\mathrm{log})$}

Fig. 1 Interprovincial species-area relationship for tropical freshwater fishes. The $z$-value is 0.89 . Data courtesy Peter Reinthal. Figure from Rosenzweig (2003) with permission.

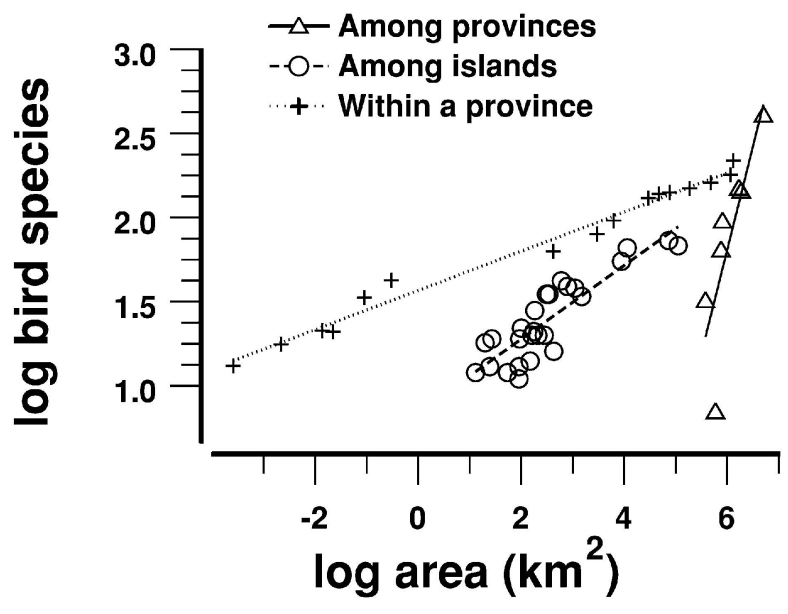

Fig. 2 Three scales of species-area curves taken from bird censuses. The steepest curve connects points from different biogeographical provinces (data on frugivores of wet tropical forests from Fleming et al. (1987) and Rosenzweig (1995)). The least steep curve connects points from different sized samples within the same province (Chilean matorral data from Cody (1975)). The archipelagic curve lies in between (Caribbean data from Wright (1981)).

the species of its mainland source pool can experience no further immigrations. In contrast, immigrants must be arriving at some positive rate on an island with no species, and an island with as many species as possible must suffer extinctions at some positive rate. Thus there has to be at least one intermediate diversity at which the two rates neutralize each other, i.e. there has to be at least one steady-state diversity.

But MacArthur and Wilson went beyond a demonstration of self-regulating diversity on islands. Their theory also predicts the existence of archipelagic SPARs: larger islands should tend to contain more habitats and, at any particular $S$, larger populations of species. Those influences would depress the extinction rate curve of a large island compared to a smaller one, and the steady-state should therefore increase with island size.

The theory of island biogeography does not predict the shape or the $z$-value of archipelagic SPARs, but it does predict that their z-values should vary. At any particular diversity, islands farther from the source of colonization should receive immigrant species at a reduced rate compared to closer islands. So two islands at different distances, but of the same area, will have different steady states. The farther island will have the lower $S$. Connecting the species-area point of this farther island to that of the source area yields a steeper line than connecting the species-area point of the nearer island (with higher $S$ ) to the source area's point. But the slope is the $z$-value, and so an island with the same area but fewer species has a higher $z$-value than its closer counterpart. 
The theory predicting interprovincial SPARs also depends on dynamics (Rosenzweig, 1975). In fact, its extinction curves are the same shape as those from island biogeography. Not so the curves describing the rate at which it receives new species, which differ considerably from island curves. Recall the definition of provinces: areas whose species originate by speciation from within. Hence, provincial dynamics depend on speciation rates and extinction rates, rather than immigration rates and extinction rates. The cumulative difference between the creative process of speciation and the destructive process of extinction determines the number of species alive in a biological province.

But existing species are the nurseries for new species; the latter always develop out of the former. Consequently, speciation rate should rise as diversity does. Hence, the slope of the speciation rate curve for a province should be positive, whereas it is negative for an island. Speciation rate curves with positive slopes do not prevent steady states in provinces - provincial steady states emerge once one considers the biogeographical ranges of species and how those ranges respond to diversity.

As diversity rises in a province, competition and predation tend to restrict individual species to smaller geographical ranges, which decrease speciation rate (for a variety of reasons including that smaller ranges produce geographical isolates at a lower rate than do larger ranges). So, as diversity grows, the speciation rate of the average species declines. That decline imposes a negative second derivative on the curve of total speciation rate. Meanwhile, as diversity grows, the total rate of extinction accelerates. The two curves intersect, producing a provincial steady-state diversity (for examples, see Fig. 3).

In summary, even with no sample-size bias, the ecologist expects to see three types of SPAR. But why should they have dissimilar z-values? Why should SPARs representing samples of one province have the gentlest slopes, those between provinces have the steepest, and those of archipelagos have slopes that lie between the other two? Again we turn to rates for our answer. A piece of a province will contain those species that the habitats of that piece can sustain, but it will have other species as well. The piece will be good enough to support individuals of these other species, and may even be sufficient to support some reproduction by them. But it will not be sufficient for those species to maintain their populations. Their dispersal into the piece keeps them there. If their dispersal rate plus the rate at which they reproduce is, together, sufficient to counterbalance their death rate, they will occur in the piece again and again.

Inspired by desert plants, Shmida \& Ellner (1984) recognized and gave a special name to populations of species that require dispersal contributions from else-

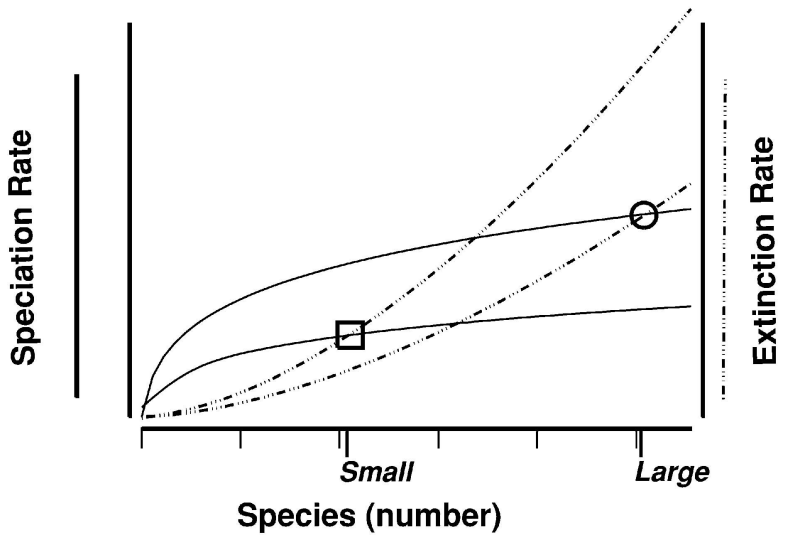

Fig. 3 Because it was much larger than today's, the natural world of 2,000 years ago had both a higher speciation-rate curve and a lower extinction-rate curve, resulting in a larger steady state (circle). The new curves predict the steady state of today's smaller natural world (box). This will be achieved only after excess extinction has reduced diversity to the point where the total rate of extinction again equals the total rate of speciation.

where. They called them sink populations. In contrast, they called sustainable populations source populations. A piece of a province has both source and sink populations, which, by extension of the metaphor, I call 'source and sink species'. Shmida and Ellner called the extra species conferred by sink populations, the "mass effect."

Now we consider islands. We take a great, imaginary blade and cut a piece of mainland free of its provincial moorings, setting it adrift in the sea. Its source species will remain, but its sink species will not. The high regular dispersal rates that they require for their maintenance will have been replaced by much lower rates of origination by rare colonization events. So the island will have fewer species than the provincial piece. A line connecting it to the area-diversity point of the entire province will be steeper than one connecting the piece to the province. Consequently, the $z$-value of the island will be larger than that of the piece.

As time unfolds, the source species of the island will suffer occasional extinctions. During most years those species will have healthy reproduction, but not during every year. All species encounter stochastic disasters now and again. The island's diversity therefore tends to decay. But accidents are rare, and the extinctions will be counterbalanced by immigrations. Thus the island will reach its steady state $S$. As we push our imaginary island farther from the province, immigrations will occur less and less frequently. The rate of flux of species on the island will slow down to reflect the lower immigration rate. The steady state declines. The line connecting the island to the area-diversity point of the entire province will grow steeper, sending its z-value higher. If we push the island far enough away, immigrations will occur so 
rarely that speciation rates will match them. Our island changes into a new, small province with a very steep $z$.

So, our attempts at theory have met with considerable success. Theory predicts the existence of four distinct SPARs, and it identifies the processes controlling each one. It tells us that SPARs within a province should and do fit power equations, albeit imprecisely. It predicts that the exponent of those equation should hover around 0.15 . It also predicts that the slopes of island SPARs should exceed those within a province, and those between provinces should exceed those of islands. We cannot yet predict the exponents ( $z$-values) of island or interprovincial SPARs, but meanwhile data tell us that the latter range from 0.6 to 1.0 and the former from 0.25 to 0.55 , and that is enough for practical purposes.

\section{Steady-state diversities in the fossil record}

Benton (1995) and some others claim that steady-state theories are irrelevant to diversity because diversity has risen fairly steadily throughout the Phanerozoic Eon, the last 550 m.y. (million years). He fits a single explosive exponential equation to animal diversities throughout the Phanerozoic, but mounting evidence now suggests that diversity has been near a steady state during most of that time.

First, the deviations from Benton's equation are heroic. Moreover, the data themselves are suspect on two grounds. They report generic or familial diversities, not species diversities. We know little about the processes that lead to the origination or extinction of such higher taxa. We cannot yet build any theory of them, and we have no basis to believe they should behave like species diversities. Moreover, all the data sets that lead to the conclusion of a steadily rising diversity share a troubling deficiency. They are uncorrected for sample-size problems.

Raup (1976) warned that, in general, older fossils are scarcer than younger ones, prejudicing us to the conclusion that older times had fewer species. The greatest bias comes in the Cenozoic (i.e. Tertiary) rocks of the last 65 m.y. These are 10 times as abundant as those of 200-400 m.y. ago, and not only do they cover more of the earth, they are often easier to work with. They tend to be unconsolidated, which means they have not turned into hard rock, and so their fossils can be recovered simply by washing away the rock matrix in water. With considerably less effort, they produce far more fossils of much better quality than consolidated rock. In my view, it is not a coincidence that most of the explosiveness of Benton's equation derives from the apparent huge increase in diversity during the Cenozoic.

Even the raw record of familial or generic diversities during the Phanerozoic does little to support a single exponential equation. From the raw data, Sepkoski
(1978) recognized three diversity eras during this time. The earliest, during the Cambrian of 500 m.y. ago, had the poorest diversities, but appeared to have reached a steady state. It was replaced by the second, a richer time, which also reached a steady state and lasted until c. 100 m.y. ago. The third, beginning in the Cretaceous, is the one in which we now live. Its raw data do seem to indicate a rapid rise in diversity and also seem to show no signs of leveling off. But, of course, the last $100 \mathrm{~m} . \mathrm{y}$. is the time of maximum bias, and recent, very careful studies of that bias (discussed below) suggest that it may be the principal or even the sole source of the apparent rise in diversity during the Cretaceous-Tertiary.

Sample-size bias pervades work in diversity. The most successful statistical tools to reduce this problem belong to a family of jackknife methods (Burnham \& Overton, 1979; Chao \& Lee, 1992; Chao et al., 1992; Lee \& Chao, 1994). Palaeobiologists are beginning to explore these methods. Meanwhile, many palaeobiologists have approached their data sets with older tools such as rarefaction analysis (e.g. Miller \& Foote, 1996). That does not eliminate the bias; rather it equalizes bias among samples. So rarefaction can be used in comparing different samples, albeit somewhat crudely.

More refined examinations of fossil diversities leave no doubt that life has often fluctuated about a steady state. Boucot (1975) showed this to be true of long time periods he called ecological-evolutionary units (EEUs). EEUs persist for tens of millions of years. Brett et al. (1996) have demonstrated the existence of temporal sub-units within EEUs that are even more stable. Focusing on the dynamics, I and my students began analyzing a particularly well structured set of samples from the Nicolet River Valley of Quebec (Bretsky \& Bretsky, 1976). The strata represent a period of some $5 \mathrm{~m}$.y. at the end of the Ordovician (440 m.y. ago), and for the latter 3.5 m.y. of this time, at least, species diversity fluctuated about a steady state (Fig. 4) (Rosenzweig, 1995).

Subsequently, others have seen steady states within the Cenozoic itself (Nichols \& Pollock, 1983; Allmon et al., 1993; Van Valkenburgh \& Janis, 1993; Alroy, 1998; Alroy et al., 2001). This is particularly damaging to Benton's interpretation, because the Cenozoic ought instead to exhibit the sharpest, easiest to document increases in diversity.

\section{What human impact will do to diversity}

For a million years, Man, the most ecologically adaptable of species, has been coming into its own, realizing its potential to compete with almost all other animals in almost all abiotic milieux. For a thousand years and at an accelerating rate, Man has been reducing the area available to most other species. Science and society have to face 


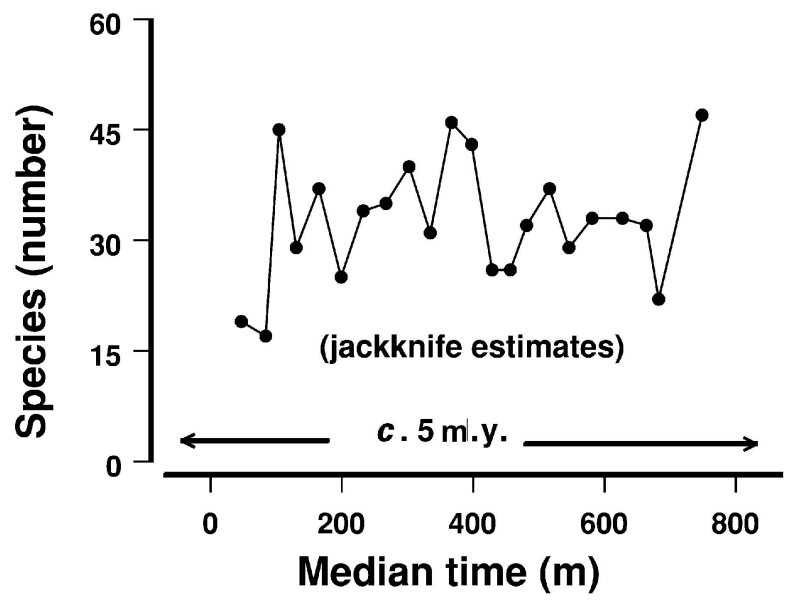

Fig. 4 An example of a steady-state in species diversity from the fossil record. Species come from the latest Upper Ordovician muddy benthos of the Nicolet River Valley, Quebec, Canada (c. 440 million years ago). Time is indicated in metres above the oldest strata. The jackknife estimator reduced the sample size bias of the raw diversities. (Adapted from Rosenzweig (1995)).

the consequences of this reduction because the number of species at diversity's steady state depends on available area. A number of estimates of this reduction exist. Vitousek et al. (1997) indicate $40-50 \%$ of the ice-free, terrestrial surface has been degraded for wild species by human use. Myers and his colleagues estimate the degradation of specific habitats: $75 \%$ of the forests (that once covered c. $40 \%$ of the world's terrestrial surface) (Myers, 1999) and 88\% of the world's most diverse habitats (Myers et al., 2000). Certainly the loss of temperate grasslands to wildlife is now close to $100 \%$. Huston (1993) estimates the average loss of ice-free, terrestrial surface area at 95\%. Marine environments have suffered much the same fate (Jackson, 2001).

Faced with the continuing loss and degradation of natural habitat, society battles to save diversity by setting aside some natural areas. Because extinction is a process that often requires many generations, this strategy has helped so far. But it will not help much longer. Area constitutes a basic inherent property of every biome, a property crucial to the dynamic functioning of its components. So it is an oxymoron to imagine a pristine biome that retains only $2 \%$ or $5 \%$ or even $10 \%$ of its original size. Instead, because of the severe loss of natural habitat, ecologists predict a new mass extinction on a scale that has not visited the earth for 65 m.y.

The optimists base their quantitative prediction on the archipelagic $z$-value (e.g. Pimm et al. 1995). The shrunken natural part of the earth, they say, has become an island. It will maintain species only according to the equation:

$S=A^{0.3}$ where $S$ and $A$ are the proportions of diversity and natural area that will remain. (Notice that $C$, the constant of Eq. 1, equals unity in Eq. 3 because, in Eq. 3, $S$ and $A$ are proportions.) According to Eq. 3, 5\% of the area will sustain about $41 \%$ of species diversity.

As diversity relaxes to satisfy the island equation, the first species to go will be the endemics, those species whose habitat gets entirely expropriated (Harte \& Kinzig, 1997). These extinctions will be deterministic and virtually instantaneous. Following them will be the sink species, those that get restricted to marginal habitats (i.e. habitats in which their death rates exceed their birth rates). These extinctions will also be deterministic in the sense that we should be able to point out the victims unambiguously by separating sink from source species (Patterson, 1990; Patterson \& Atmar, 2000).

Conservation's two strategies of reservation and restoration have stayed the imposition of the island equation, and may even have reduced its severity (Fig. 5). Instead of saving natural areas randomly, we diversified what we saved, deliberately focusing on preserving or restoring the habitats most likely to vanish entirely. Hence, we considerably reduced the likelihood that any species would lose everything, including its sink habitats. That transferred some extinction of endemics to the category of extinction of sink species, slowing down the course of mass extinction because some individuals of sink species not only survive, they also reproduce. Thus the deterministic extinction of a sink species takes more time than the instantaneous extinction of an endemic.

Nevertheless, diversity's decline will not halt after our small, new natural world reaches levels of island-like

Traditional conservation

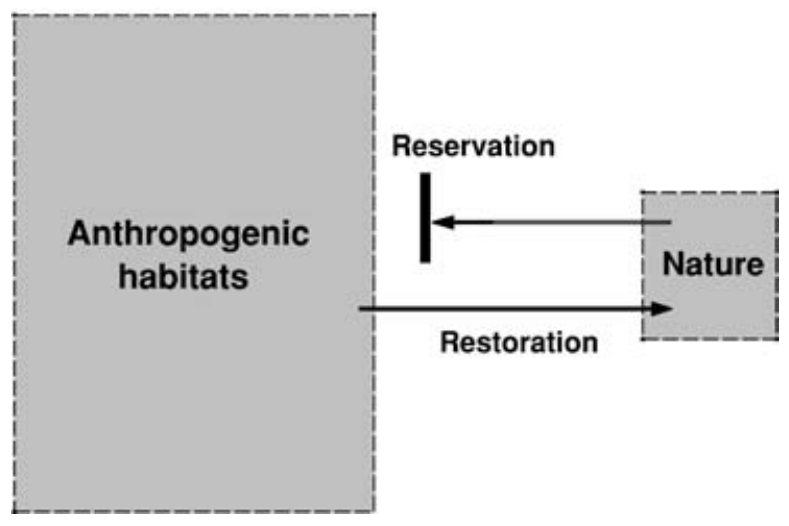

Fig. 5 Conservation's two dominant strategies, reservation and restoration, view the world as divided into two sorts of areas: natural set-asides and places ruined by the activities of people. Reservation prevents further areas from becoming degraded. Restoration returns areas to the high quality pool. 
diversity. The world of nature reserves is not an island but a shrunken province. Its source pool is the past. Species that become extinct in it cannot immigrate from the past to recolonize the world of the future. So, like any evolutionarily independent province, our miniaturized natural world must seek its future steady state along the interprovincial SPAR, not the island SPAR.

The $z$-value of interprovincial SPARs is approximately unity, so its governing equation is approximately:

$S=A$

where, as in Eq. 3, $S$ and $A$ are expressed as proportions in order to transform the constant, $C$, of Eq. 1, to unity. Thus our losses of species should be approximately linear. Lose $10 \%$ of the natural world's surface and we save about $90 \%$ of its species. Lose $95 \%$ and save only $5 \%$ of the species.

Once our mini-world has dwindled to island-like diversity, the remaining species left will all begin with at least one source population. So how could further deterioration occur? Part of the answer is accidents. Source species can vanish merely because they encounter a series of poor years. In addition, global warming may change them into sink species by pushing their remaining habitats out of all reserves and into cornfields or the sea (Peters \& Darling, 1985). New parasites and diseases will also emerge to take their toll. Thus, relaxation below the island-like steady state will come from inflated extinction rates.

Misfortunes that eradicate successful species have always accompanied life. In ordinary times, life replaces such losses by speciation. However, this time, because constricted geographic ranges produce fewer isolates, the loss of area will also depress the speciation rate curve. One may hope that the massive anthropogenic fragmentation of species ranges may compensate somewhat, but these fragments are likely to prove too small (Rosenzweig, 2001) and ephemeral to help. Moreover, many species are being restricted to a single reserve, with no chance whatsoever of further allopatric speciation. The loss of ecological theatre is changing the evolutionary play. Speciation will not keep up with the losses.

Previous mass extinctions were a violent interruption and perturbation of steady-state diversities rather than a change in speciation and extinction rate curves. Afterwards, background conditions returned and life gradually recovered its steady states under the influence of more or less the same speciation rate curves as before the catastrophe. The process of re-achieving a steady state after the current biotic crisis, however, will not resemble any previous recovery from a mass extinction (Rosenzweig, 2001).

Although a balance will eventually be restored, the mass extinctions of our era represent a gradual relax- ation to a new steady state. This new state is dictated by the shrunken area available to nature and by the shrunken speciation rates that must characterize such a shrunken area. For restoration of a steady state, enough species must vanish so that the total extinction rate of those that remain declines to the level of their total speciation rate (Fig. 3). Recovery of steady-state dynamics will occur as soon as the mass extinction is over, i.e. after complete relaxation. To a large extent, the trajectory of stochastic extinctions - not the trajectory of originations - will determine how long the process will take. Furthermore, at the steady-state of the future, when life is again replacing its losses by speciation, it will be decimated of its richness.

Human pressure may greatly accelerate the relaxation process by increasing extinction rates. Various human activities suggest this. We increasingly commingle evolutionarily separate provincial biotas, creating the New Pangaea and introducing predatory and competitive threats from exotic species (Mooney \& Cleland, 2001). We rapidly transport novel diseases and parasites around the world, we simplify biotic temporal regimes (for example by limiting disturbances such as fire), and we are warming the globe. The National Research Council (1995) implicates exotic species (p. 37,38) or lack of adequate disturbance (p.105) as the root cause in endangering a significant proportion of threatened US species. But global warming may constitute the worst threat of all - by altering the basic abiotic conditions of reserves, it can destroy their ability to do much of their job. When the earth was covered with contiguous tracts of natural habitat, species could track such changes, moving to keep up with the shifts in location of their favoured habitats and so avoiding extinction (Davis, 1983; Coope, 1987; Brett, 1998). But today, with natural habitats restricted to patches of reserves, this is not possible. Meanwhile, we show little sign of abandoning the thoughtless destruction of whatever unprotected natural habitat remains.

We stand at the edge of an abyss as deep as the greatest known catastrophe in the history of life, the PermoTriassic mass extinction, which, some 225 m.y. ago, exterminated more than $95 \%$ of the earth's species. Life eventually recovered from that catastrophe but there is no reason to expect life ever to recover from this one. The Permo-Triassic catastrophe occurred because of a temporary disaster. Recovery commenced as soon as environmental conditions returned to their more usual states. But this time, we are the disaster and we have no intention of going away - although we can do something to step away from the precipice.

Today, conservation biology battles to save species by using two dominant tactics: reservation ecology and restoration ecology. Unhappily, owing to the power of 
area, these two cannot do much by themselves. No conservationist seriously believes that we can reserve much more than the $5 \%$ or $10 \%$ that now remains, and many will admit that the human population is likely to continue expanding. If we use only reservation ecology and restoration ecology, it would seem that we are doomed to lose nearly every species alive today. Reservation and restoration ecology must be supplemented. "Conservation philosophy, science, and practice must be framed against the reality of human-dominated ecosystems, rather than the separation of humanity and nature underlying the modern conservation movement" (Western, 2001). Fortunately, some people have begun this work.

\section{Reconciliation ecology}

Today, conservationists and ecologists are pioneering a new area of research that will make long-term diversity conservation possible. I call it reconciliation ecology. Reconciliation ecology discovers how to modify and diversify anthropogenic habitats so that they harbor a wide variety of wild species. In essence, it seeks techniques to give many species back their geographical ranges without taking away ours (Fig. 6). Thus it is trying to grow the earth back, to expand the area available to nature. That will establish a steady-state diversity far greater than would be available if conservation biologists restrict themselves to the areas afforded by set-asides alone. A growing number of examples demonstrate that reconciliation ecology can work (Rosenzweig, 2003). I will describe a few in the rest of the paper.

\section{Reconciliation Ecology}

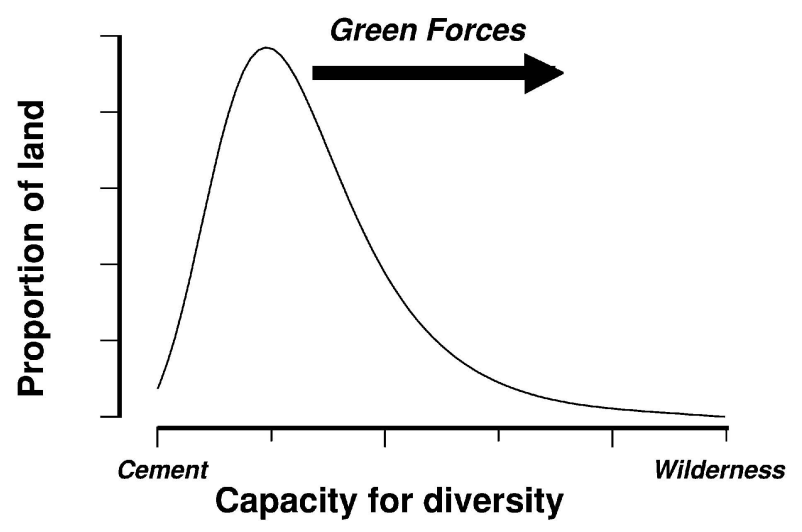

Fig. 6 The capacity of land to support diversity. Reconciliation ecology treats this as a continuous variable. It seeks techniques to move land to the right along that continuum. This it accomplishes by redesigning human habitats to give some species back their geographical ranges without taking away ours.

\section{Reconciliation in agricultural sites}

Because agricultural uses dominate most of the land areas that people have taken for themselves, perhaps the most important cases of reconciliation ecology are those associated with agriculture. Led by Gretchen Daily (Daily et al., 2001), John Vandermeer and Yvette Perfecto (Vandermeer \& Perfecto, 1995), and Russell Greenberg (Greenberg et al., 1997), 'Countryside Biogeography' is showing that some styles of land use, especially those of traditional agriculture, are already compatible with the needs of many species. Sometimes the compatibility of diversity and agriculture occurs quite accidently, sometimes it is deliberate. Such compatibility exists in pasturelands, croplands, plantations and timberlands. It comes from rich and poor countries, sponsored by private or governmental agencies. The following examples illustrate the variety.

\section{Cardamom}

Growers maintain many tree species in their cardamom Elettaria cardamomum plantations. They do so to provide shade for the herb and a steady supply of nectar for its pollinators, principally honey bees. Bees visit 37 tree species in the plantations, of which 10 supply both nectar and pollen, three nectar only and the rest pollen only. From May to September, flowers are not very abundant, however, and biologists are working to find more plant species to fill in this temporal gap and provide a steadier nectar supply for the bees (Kuruvilla et al., 1995). As they do so, they will be practicing deliberate reconciliation ecology.

Pest control

Reconciliation may have considerable potential for minimizing losses to agricultural pests. For example, California viticulturists rely on a parisitoid wasp for biological control of leafhoppers in their vineyards (Doutt \& Nataka, 1973), but the wasps require prey throughout the year and the grape leafhoppers become inactive in winter. So grape growers planted patches of native blackberries in shady spots near vineyards to maintain wasp populations. Each spring, wasps quickly re-invade the vineyards from the blackberry patches, thus keeping pest populations down. Although the growers' goal was not to alleviate any crisis in biodiversity, their method helps to achieve precisely that. The mosaic of habitats they designed includes patches suitable for all the native species associated with blackberries.

\section{Pasturelands}

Pasturelands constitute a major part of the world's agricultural surface, and provide some encouraging examples of reconciliation. For example, the Ocosingo Valley in 
Chiapas, Mexico, has extensive pastureland, as well as patches of managed and unmanaged woodlands, and patches of Acacia pennatula, a species whose stems and branches are too spiny for cattle to eat (Greenberg et al., 1997). Consequently, the ranchers eradicate acacia from their pastures. Yet, the acacia pods contain high amounts of protein and make a valuable, seasonal cattle food. The ranchers also need the acacia for fence posts. Therefore, ranchers maintain small woodlots composed almost exclusively of acacia. Greenberg et al. (1997) censused birds in 18 different Chiapas habitats, including the acacia woodlots, and found the latter to be havens for a large number of overwintering songbirds. The woodlots have more species (18) and more individuals than any other habitat, including 'natural' forest at low elevation. The way the ranchers of the Ocosingo manage their woodlots provides a splendid case of reconciliation by accident.

\section{Reconciliation of disappearing ecosystems}

\section{Longleaf pine forest}

Timberlands also cover a lot of land surface. Reconciling them will be crucial. An exciting example comes from a project jointly planned and operated by the US Air Force and The Nature Conservancy. To save longleaf pine forest and its endangered species such as the redcockaded woodpecker, they undertook novel, carefully studied and continuous management in Eglin Air Force base, a large installation in Florida (McWhite et al., 1993). Longleaf pine forests once covered more than 36 million hectares along the eastern coastal plain of the USA (Biondo, 1997), but by 1992 as little as 2,000 hectares, only $0.006 \%$, of old-growth longleaf pine remained. Eglin Air Force Base just east of Pensacola in the Florida panhandle encompasses 187,555 hectares and most of that used to be pineland. In 1992 it retained only 693 hectares of old-growth longleaf pine, and even these were not reproducing because they were heavily infested with various species of oak trees in the understory.

In 1993 the Air Force began to restore the forest. They removed large numbers of other species of pines. They planted more than 3 million longleaf seedlings, and annually they are burning substantial fractions of the forest's understory. As a result, longleaf pine now dominates more than 80,000 hectares of Eglin Air Force Base. The Air Force has also helped the rare animals of the pineland, especially, the red-cockaded woodpecker, which excavates its nest holes in living longleaf pine trees. Air Force crews drill artificial nest cavities in the trunks of the healthy young longleaf pines. Red-cockaded woodpeckers nest in 30\% of these holes, and their population has begun to grow.
Meanwhile the base continues to develop and test various weapons, thousands of people live on the base in its 2,380 homes, and thousands of others buy permits to camp, fish and hunt in its pineland. Timbering has actually increased and is profitable. This is not restoration ecology. Never before has there been a longleaf pine forest like this one.

\section{Eilat salt marsh}

The longleaf-pine-forest ecosystem confers many practical benefits on humans. But reconciliation can also be practical in ecosystems that produce no direct benefits. Consider the case of the salt marsh along the migratory flyway that traverses Israel. Until 30 years ago a $12 \mathrm{~km}^{2}$ natural salt marsh in Eilat, Israel, provided a critical feeding stop on the migratory route of perhaps a third of all the bird individuals in Europe and western Asia. But the marsh was totally destroyed by resort development. Just before it disappeared entirely, Ruven Yosef created a single patch of non-natural salt marsh to save at least a fraction of the 257 species that use the route (Cherrington, 1999). Yosef's patch of salt marsh little resembles its predecessor or any natural habitat. It is carefully built up, contoured and planted on a refuse dump. Its soil came from the excavations of the hotelconstruction industry and, further linking it to the works of people, it is regularly irrigated with treated, nutrient-rich sewage water. It has roughly four times the productivity of the natural marsh it replaced.

\section{Backyard Wildlife Habitat ${ }^{T M}$}

Although not as extensive as agricultural lands, residential areas also offer important opportunities for reconciliation ecology. Recognizing this opportunity for almost three decades, the US National Wildlife Federation has sponsored a campaign called Backyard Wildlife Habitat ${ }^{\mathrm{TM}}$. It encourages people to bring nature to their own homes. So far it has enrolled more than 20,000 private little patches of nature. They vary in area from a few hectares to a single balcony. All try to create a modified human habitat that provides for the needs of at least some wildlife (Tufts \& Loewer, 1995). A more specialized residential target for reconciliation is the American lawn (Bormann et al., 2001). It is monotonous, depauperate and nearly sterile, and it covers a significant fraction of suburbia. Meanwhile, natural prairie barely survives. But we know quite a lot about how to get patches of prairie to flourish in the green spaces around houses.

\section{Reconciliation for disappearing species}

In a number of the previous examples reconciliation ecology was associated with reinventing a scarce or even an endangered ecosystem. But reconciliation may also 
focus on preserving a single rare species. This section will look at a few such cases.

\section{Bluebirds}

Eastern bluebirds Sialia sialis once thrived in human habitats of North America but today are quite uncommon. Their basic problems are two aggressive, alien, abundant bird species that also like to nest in holes near people: house sparrows and European starlings. These species evict the otherwise successful bluebirds. Starlings also eat the berries that the bluebirds need to survive during the winter. People discovered that a nest box with a hole $3.8 \mathrm{~cm}$ in diameter suited bluebirds but excluded starlings (Davis \& Roca, 1995). Then they found that house sparrows do not like nest boxes only 10 to $13 \mathrm{~cm}$ deep. In 1979, the North American Bluebird Society was founded and began to encourage people to deploy appropriate nestboxes on their property. Bluebird numbers are now recovering.

\section{Natterjack toads}

Reconciliation efforts in England on behalf of the natterjack toad Bufo calamita constitute a detailed, multifaceted and sustained effort by c. 50 researchers over 25 years, culminating in the development and installation of habitats to save this species in the United Kingdom (Denton et al., 1997). The work first centered on characterizing the natterjack's niche. The natterjack toad is a pioneer amphibian that lives in open vegetation surrounding eutrophic pools of coastal dunes and oligotrophic pools of inland heaths. Unlike its chief competitor, Bufo bufo, it burrows in sand. When foraging at night it operates at a body temperature $1.4^{\circ} \mathrm{C}$ higher than $B$. bufo, and loses weight if forced to forage in dense, cooler vegetation. This helps to explain why its population declines during succession as tall vegetation, such as birch, gorse and bracken, begins to invade and shade its habitat. The increased shade also lowers the water temperature of the pools, slowing the development of natterjack tadpoles and subjecting them to damaging competition from B. bufo.

The natterjack team cleared dense vegetation and re-introduced grazing to maintain the early stages of succession. They fought acidification by adding $\mathrm{Ca}(\mathrm{OH})_{2}$ to natterjack ponds every year or two, or scraping the sulfate-rich silt from the bottom of the ponds. They removed some B. bufo and they built $c .200$ new ponds, often using old bomb craters and active golf courses. At all sites with new ponds, $B$. calamita used at least one of them, and usually most of them, within a year or two. The new ponds rescued or increased natterjack populations in two-thirds of the sites. The grazing has returned a small profit.
Shrikes

Many species of shrikes are endangered (Yosef \& Lohrer, 1995). In European and American countries where bird counts are a tradition, shrike populations have declined by over $50 \%$. Some countries have lost entire species; Switzerland, for example, has lost two of its four, as has the Czech Republic. Ruven Yosef found that loggerhead shrikes Lanius ludovicianus, like most shrikes, prefer to hunt by sitting on a post or branch, scanning the ground around them, and then pouncing on an insect. Cattle ranches often have suitable fields full of insects, but few perches. Yosef installed cheap fence posts in a working cattle ranch in central Florida and greatly improved its value for shrikes (Yosef \& Grubb, 1994). Within the first spring, territories with the extra fence posts shrank by an average of $77 \%$, and the loggerhead shrike population increased $60 \%$. The smaller territories also helped nestlings survive. Parent birds in smaller territories had $33 \%$ more successful clutches than controls, and raised $29 \%$ more chicks per successful clutch. Other species of shrikes are also being helped by similar methods of reconciliation (Devereux 1998; van Nieuwenhuyse 1998; Schön 1998).

\section{Afterword}

The path that leads to reconciled human habitats is hardly trouble free. Attitudes will need to change. Public and private institutions will need to adapt. An immense amount of research lies ahead as we accumulate a library of the habitat requirements of myriad species, and learn how to combine them (National Research Council, 2001). We will even need to alter the way we manage our reserves. Until we have tried reconciliation, until we have seen how willing people will be to employ it, we cannot be sure how much it will help. We can only say that it will. Yet, despite its difficulties and uncertainties, we must employ as much reconciliation as we can. Our knowledge of species-area laws demands it. Evidence indicates that we cannot preserve the large-scale at the tiny scale. If the area available to wild species remains very low or declines even further, even our biotic preserves will not be able to maintain their diversities for very long.

Reconciliation ecology addresses the new, sterile habitats in which most species cannot function at all. It brings them back to life. If this new strategy of conservation biology spreads and influences a substantial proportion of the earth's area, it can halt the current mass extinction.

\section{Acknowledgements}

Ron Pulliam rescued me from despair. At first I was afraid that the interprovincial SPAR meant that nothing 
could be done to save diversity. But he said simply, "Cheer up, Mike. Things aren't that bad." I am glad I believed him. Arnie Miller taught me the significance of the fact that Cenozoic fossils very often come from unconsolidated deposits. Martin Fisher, Andrew Balmford and two anonymous reviewers helped with the manuscript. Gordon Orians, David Policansky, Margaret Mayfield and Caleb Gordon suggested some of the examples of reconciliation. Kudos to the late G. E. Hutchinson for the image of the ecological theater and the evolutionary play. Thanks to Ruven Yosef for information, inspiration and hospitality.

\section{References}

Allmon, W.D., Rosenberg, G., Portell, R.W. \& Schindler, K.S. (1993) Diversity of Atlantic coastal plain mollusks since the Pliocene. Science, 260, 1626-1629.

Alroy, J. (1998) Equilibrial diversity dynamics in North American mammals. In Biodiversity Dynamics: Turnover of Populations, Taxa and Communities (eds M.L. McKinney \& J. A. Drake), pp. 232-287. Columbia University Press, New York, USA.

Alroy, J., Marshall, C.R., Bambach, R.K., Bezusko, K., Foote, M., Fuersich, F.T., Hansen, T.A., Holland, S.M., Ivany, L.C., Jablonski, D., Jacobs, D.K., Jones, D.C., Kosnik, M.A., Lidgard, S., Low, S., Miller, A.I., Novack-Gottshalle, P.M., Olszewski, T.D., Patzkowsky, M.E., Raupf, D.M., Roy, K., Sepkoski, J.J., Jr., Sommers, M.G., Wagner, P.J. \& Webber, A. (2001) Effects of sampling standardization on estimates of phanerozoic marine diversification. Proceedings of the National Academy of Sciences (USA), 98, 6261-6266.

Arrhenius, O. (1921) Species and area. Journal of Ecology, 9, 95-99.

Benton, M.J. (1995) Diversification and extinction in the history of life. Science, 268, 52-58.

Biondo, B. (1997) In defense of the longleaf pine. Nature Conservancy, 47(4) (4 (September/October)), 10-17.

Bormann, F.H., Balmori, D. \& Geballe, G.T. (2001) Redesigning the American Lawn; A Search for Environmental Harmony. 2nd Ed. Yale University Press, New Haven, USA.

Boucot, A.J. (1975) Evolution and Extinction Rate Controls. Elsevier Scientific Publications, Amsterdam, Netherlands.

Bretsky, P.W. \& Bretsky, S.W. (1976) The maintenance of evolutionary equilibrium in Late Ordovician benthic marine invertebrate faunas. Lethaia, 9, 223-233.

Brett, C.E. (1998) Sequence stratigraphy, palaeoecology, and evolution: biotic clues and responses to sea-level fluctuations. Palaios, 13, 241-262.

Brett, C.E., Ivany, L.C. \& Schopf, K.M. (1996) Coordinated stasis: an overview. Palaeogeography, Palaeoclimatology, Palaeoecology, 127, 1-20.

Burnham, K.P. \& Overton, W.S. (1979) Robust estimation of population size when capture probabilities vary among animals. Ecology, 60, 927-936.

Chao, A. \& Lee, S.-M. (1992) Estimating the number of classes via sample coverage. Journal of the American Statistical Association, 87, 210-217.
Chao, A., Lee, S.-M. \& Jeng, S.-L. (1992) Estimating population size for capture-recapture data when capture probabilities vary by time and individual animal. Biometrics, 48, 201-216.

Cherrington, M. (1999) The falcon and the firebrand. Earthwatch, May/June, 39-47.

Cody, M.L. (1975) Towards a theory of continental diversities: bird distribution over mediterranean habitat gradients. In Ecology and Evolution of Communities (eds M.L. Cody \& J.M. Diamond), pp. 214-257. Harvard University, Cambridge, USA.

Coope, G.R. (1987) The response of late Quaternary insect communities to sudden climatic changes. In Organization of Communities Past and Present (eds J.H.R. Gee \& P.S. Giller), pp. 421-438. Blackwell Scientific, Oxford, UK.

Daily, G., Ehrlich, P.R. \& Sánchez-Azofeifa, G.A. (2001) Countryside biogeography: use of human-dominated habitats by the avifauna of southern Costa Rica. Ecological Applications, 11, 1-13.

Davis, M.B. (1983) Holocene vegetational history of the eastern United States. In Late-Quaternary Environments of the United States (ed H.E. Wright, Jr.), pp. 166-181. University of Minnesota Press, Minneapolis, USA.

Davis, W.H. \& Roca, P. (1995) Bluebirds and their Survival. The University Press of Kentucky, Lexington, USA.

Denton, J.S., Hitchings, S.P., Beebee, T.J.C. \& Gent, A. (1997) A recovery program for the natterjack toad (Bufo calamita) in Britain. Conservation Biology, 11, 1329-1338.

Devereux, C. (1998) The fiscal shrike. Africa - Birds \& Birding, 3, $52-57$.

Doutt, R.L. \& Nataka, J. (1973) The Rubus leafhopper and its egg parasitoid: an endemic biotic system useful in grape pest management. Environmental Entomology, 2, 381-386.

Durrett, R. \& Levin, S. (1996) Spatial models for species-area curves. Journal of Theoretical Biology, 179, 119-127.

Fisher, R.A., Corbet, A.S. \& Williams, C.B. (1943) The relation between the number of species and the number of individuals in a random sample of an animal population. Journal of Animal Ecology, 12, 42-58.

Fleming, T.H., Breitwisch, R. \& Whitesides, G.H. (1987) Patterns of tropical vertebrate frugivore diversity. Annual Review of Ecology and Systematics, 18, 91-109.

Greenberg, R., Bichier, P. \& Sterling, J. (1997) Acacia, cattle and migratory birds in southeastern Mexico. Biological Conservation, 80, 235-247.

Harte, J. \& Kinzig, A. (1997) On the implication of species-area relationships for endemism, spatial turnover, and food web patterns. Oikos, 80, 417-427.

Harte, J., Kinzig, A. \& Green, J. (1999) Self-similarity in the distribution and abundance of species. Science, 284, 334-336.

Hubbell, S.P. (2001) The Unified Neutral Theory of Biodiversity and Biogeography. Princeton University Press, Princeton, USA.

Huston, M. (1993) Biological diversity, soils, and economics. Science, 262, 1676-1680.

Jackson, J.B.C. (2001) What was natural in the coastal oceans? Proceedings of the National Academy of Sciences (USA), 98, 5411-5418.

Kuruvilla, K.M., Radhakrishnan, V.V. \& Madhusoodanan, K.J. (1995) Small cardamom plantations - floristic calendar and bee pasturage trees. Journal Environmental Resources, 3, 32-33.

Lawton, J. (1999) Are there general laws in ecology? Oikos, 84, 177-192. 
Lee, S.-M. \& Chao, A. (1994) Estimating population size via sample coverage for closed capture-recapture models. Biometrics, 50, 88-97.

Leitner, W.A. \& Rosenzweig, M.L. (1997) Nested species-area curves and stochastic sampling: a new theory. Oikos, 79, 503-512.

MacArthur, R.H. \& Wilson, E.O. (1967) The Theory of Island Biogeography. Princeton University Press, Princeton, USA.

May, R.M. (1975) Patterns of species abundance and diversity. In Ecology and Evolution of Communities (eds M.L. Cody \& J.M. Diamond), pp. 81-120. Belknap Press of Harvard University Press, Cambridge, USA.

McGill, B. \& Collins, C. (2003) A unified theory for macroecology based on spatial patterns of abundance. Evolutionary Ecology Research, 5, 469-492.

McWhite, R.W., Green, D.R., Petrick, C.J., Seiber, S.M. \& Hardesty, J.L. (1993) Natural Resources Management Plan, Eglin Air Force Base, Florida. US Dept. of the Air Force, Eglin Air Force Base, Florida, USA.

Miller, A.I. \& Foote, M. (1996) Calibrating the Ordovician radiation of marine life: implications for Phanerozoic diversity trends. Paleobiology, 22, 304-309.

Mooney, H.A. \& Cleland, E.E. (2001) The evolutionary impact of invasive species. Proceedings of the National Academy of Sciences (USA), 98, 5446-5451.

Myers, N. (1999) Everyday extinctions in embattled forests. Nature, 400, 231-232.

Myers, N., Mittermeier, R.A., Mittermeier, C.G., da Fonseca, G.A.B. \& Kent, J. (2000) Biodiversity hotspots for conservation priorities. Nature, 403, 853-858.

National Research Council. (2001) Grand Challenges in Environmental Sciences. National Academy Press, Washington, DC, USA.

National Research Council. (1995) Science and the Endangered Species Act. National Academy Press, Washington, DC, USA.

Nichols, J.D. \& Pollock, K.H. (1983) Estimating taxonomic diversity, extinction rates, and speciation rates from fossil data using capture-recapture models. Paleobiology, 9, 150-163.

Patterson, B.D. (1990) On the temporal development of nested subset patterns of species composition. Oikos, 59, 330-342.

Patterson, B.D. \& Atmar, W. (2000) Analyzing species composition in fragments. In Isolated Vertebrate Communities in the Tropics (ed G. Rheinwald), pp. 9-24, Bonn Zool. Monogr. 46.

Peters, R.L. \& Darling, J.D.S. (1985) The greenhouse effect and nature reserves. Bioscience, 35, 707-717.

Pimm, S.L., Russell, G.J., Gittelman, J.L. \& Brooks, T.M. (1995) The future of biodiversity. Science, 269, 347-350.

Preston, F.W. (1962) The canonical distribution of commonness and rarity. Ecology, 43, 185-215; 410-432.

Preston, F.W. (1960) Time and space and the variation of species. Ecology, 41, 785-790.

Raup, D.M. (1976) Species diversity in the Phanerozoic: an interpretation. Paleobiology, 2, 289-297.

Rosenzweig, M.L. (2001) Loss of speciation rate will impoverish future diversity. Proceedings of the National Academy of Sciences (USA), 98, 5404-5410.

Rosenzweig, M.L. (1975) On continental steady states of species diversity. In Ecology and Evolution of Communities (eds M.L. Cody \& J.M. Diamond), pp. 121-140. Belknap Press of Harvard University Press, Cambridge, USA.

Rosenzweig, M.L. (1995) Species Diversity in Space and Time. Cambridge University Press, Cambridge, UK.

Rosenzweig, M.L. (2003) Win-Win Ecology: How Earth's Species Can Survive in the Midst of Human Enterprise. Oxford University Press, New York, USA.

Rosenzweig, M.L., Turner, W.R., Cox, J.G. \& Ricketts, T.H. (2003) Estimating diversity in unsampled habitats of a biogeographical province. Conservation Biology, 17, in press.

Rosenzweig, M.L. \& Ziv, Y. (1999) The echo pattern in species diversity: pattern and process. Ecography, 22, 614-628.

Schön, M. (1998) Conservation measures and implementation for the great grey shrike (Lanius excubitor) in the southwestern Schwäbische Alb of southwestern Germany. In Shrikes of the World - II: Conservation Implementation (eds R. Yosef \& F. Lohrer), pp. 68-73. International Birdwatching Center in Eilat, Eilat, Israel.

Sepkoski, J.J., Jr. (1978) A kinetic model of Phanerozoic taxonomic diversity I. Analysis of marine orders. Paleobiology, 4, 223-251.

Shmida, A. \& Ellner, S. (1984) Coexistence of plant species with similar niches. Vegetatio, 58, 29-55.

Tufts, C. \& Loewer, P. (1995) Gardening for Wildlife. Rodale Press, Emmaus, USA.

Van Nieuwenhuyse, D. (1998) Conservation opportunities for the red-backed shrike (Lanius collurio). In Shrikes of the World - II: Conservation Implementation (eds R. Yosef \& F. Lohrer), pp. 79-82. International Birdwatching Center in Eilat, Eilat, Israel.

Van Valkenburgh, B. \& Janis, C.M. (1993) Historical diversity patterns in North American large herbivores and carnivores. In Species Diversity in Ecological Communities: Historical and Geographical Perspectives (eds R. Ricklefs \& D. Schluter), pp. 330-340. University. of Chicago Press, Chicago, USA.

Vandermeer, J. \& Perfecto, I. (1995) Breakfast of Biodiversity: the Truth about Rain Forest Destruction. Institute for Food and Development Policy, Oakland, USA.

Vitousek, P., Mooney, H., Lubchenco, J. \& Melillo, J. (1997) Human domination of Earth's ecosystems. Science, 277, 494-499.

Von Humboldt, F.H.A. (1807) Essai sur la geographie des plantes. von Humboldt, Paris, France.

Western, D. (2001) Human-modified ecosystems and future evolution. Proceedings of the National Academy of Sciences (USA), 98, 5458-5465.

Williams, C.B. (1943) Area and the number of species. Nature, $152,264-267$.

Williams, C.B. (1964) Patterns in the Balance of Nature. Academic Press, London, UK.

Wissel, C. \& Maier, B. (1992) A stochastic model for the speciesarea relationship. Journal of Biogeography, 19, 355-361.

Wright, S.J. (1981) Intra-archipelago vertebrate distibutions: the slope of the species-area relation. American Naturalist, 118, 726-748.

Yosef, R. \& Grubb, T.C., Jr. (1994) Resource dependence and territory size in loggerhead shrikes (Lanius ludovicianus). Auk, $111,465-469$.

Yosef, R. \& Lohrer, F.E., eds (1995) Shrikes (Laniidae) of the World: Biology and Conservation. Proceedings of the Western Foundation of Vertebrate Zoology, 6, 1-343. 